\title{
Drug Repurposing in the Treatment of Traumatic Brain Injury
}

\author{
Michael K. Ghiam ${ }^{1 *}$, Shrey D. Patel2, Alan Hoffer ${ }^{3}$, Warren R. Selman ${ }^{3}$, Barry J. Hoffer ${ }^{3}$ \\ and Michael E. Hoffer ${ }^{1,4}$
}

${ }^{1}$ Department of Otolaryngology, University of Miami Miller School of Medicine, Miami, FL, United States, ${ }^{2}$ University of Miami Miller School of Medicine, Miami, FL, United States, ${ }^{3}$ Department of Neurological Surgery, Case Western Reserve University School of Medicine, Cleveland, $\mathrm{OH}$, United States, ${ }^{4}$ Department of Neurological Surgery, University of Miami Miller School of Medicine, Miami, FL, United States

\section{OPEN ACCESS}

Edited by:

Anna R. Carta,

University of Cagliari, Italy

Reviewed by:

Shaul Schreiber,

Sourasky Medical Center, Israel

Feixiong Cheng,

Cleveland Clinic, United States

Li-Ru Zhao

Upstate Medical University,

United States

${ }^{*}$ Correspondence:

Michael K. Ghiam

Michael.ghiam@jhsmiami.org

Specialty section:

This article was submitted to

Neuropharmacology,

a section of the journal

Frontiers in Neuroscience

Received: 30 November 2020

Accepted: 19 February 2021

Published: 23 March 2021

Citation:

Ghiam MK, Patel SD, Hoffer A,

Selman WR, Hoffer BJ and Hoffer ME

(2021) Drug Repurposing in

the Treatment of Traumatic Brain

Injury. Front. Neurosci. 15:635483.

doi: 10.3389/fnins.2021.635483
Traumatic brain injury (TBI) is the most common cause of morbidity among trauma patients; however, an effective pharmacological treatment has not yet been approved. Individuals with $\mathrm{TBI}$ are at greater risk of developing neurological illnesses such as Alzheimer's disease (AD) and Parkinson's disease (PD). The approval process for treatments can be accelerated by repurposing known drugs to treat the growing number of patients with TBI. This review focuses on the repurposing of $\mathrm{N}$-acetyl cysteine (NAC), a drug currently approved to treat hepatotoxic overdose of acetaminophen. NAC also has antioxidant and anti-inflammatory properties that may be suitable for use in therapeutic treatments for TBI. Minocycline (MINO), a tetracycline antibiotic, has been shown to be effective in combination with NAC in preventing oligodendrocyte damage. (-)-phenserine (PHEN), an anti-acetylcholinesterase agent with additional noncholinergic neuroprotective/neurotrophic properties initially developed to treat $A D$, has demonstrated efficacy in treating TBI. Recent literature indicates that NAC, MINO, and PHEN may serve as worthwhile repositioned therapeutics in treating TBI.

Keywords: traumatic brain injury, concussion, $\mathrm{N}$-acetyl cysteine, minocycline, phenserine

\section{BACKGROUND}

Traumatic brain injury (TBI) is a major public health issue with 69 million cases globally each year and plays a role in approximately one-third of all injury-related deaths in the United States (Faul et al., 2010; Dewan et al., 2018). North America has the highest reported incidence of TBI in the world with 1299 cases per 100,000 individuals at an estimated cost of $\$ 3.84$ billion (Faul et al., 2007, 2010; Dewan et al., 2018). TBI cases are commonly classified as: mild (awake and oriented); moderate (significantly confused but able to follow commands); and severe (prolonged impaired consciousness and inability to follow commands) based on parameters of the Glasgow Coma Scale (Jennett et al., 1981). Most cases are mild in severity, allowing for the opportunity to recover from initial symptoms. However, despite initial recovery, patients remain at risk of developing late secondary neurodegenerative disorders such as Alzheimer's disease (AD) (e.g., memory loss) and Parkinson's disease (PD) (e.g., tremor and shuffling gait) (Goldman et al., 2006; Tagliaferri et al., 2006; Chauhan, 2014; Djordjevic et al., 2016; Mendez, 2017). Drugs utilized in treating TBI may work to protect brain areas that are at increased risk in the acute and delayed setting (Du et al., 2016). The mechanisms of injury following cortical impact involve neuroinflammatory pathways, apoptotic cell death, and glutamic toxicity (Ray et al., 2002). The multifaceted and undefined nature 
of TBI makes it difficult, time consuming, and expensive to develop novel treatment strategies. Drug repurposing can provide a fast-tracked route toward developing effective therapies for TBI. Several drugs under investigation include $\mathrm{N}$-acetyl cysteine (NAC), minocycline (MINO), (-)-phenserine, progesterone, propranolol, and valproic acid (Eakin et al., 2014; Xiong et al., 2015; Hoffer et al., 2017). NAC and MINO have been approved by Federal and Drug Administration for the treatment of acetaminophen induced hepatotoxicity and bacterial infections, respectively (Adminstration, 1971; Prescott et al., 1979).

\section{PATHOPHYSIOLOGY OF TRAUMATIC BRAIN INJURY}

Primary TBI occurs as a result of physical trauma to the head, causing neuronal damage, and neuroinflammatory events. The manipulation of neuronal membranes dysregulates ion flow. Neuroinflammation is induced by increased microglial activity and depletion of mitochondrial glutathione (GSH), a key antioxidant compound. GSH reduction combined with increased intracellular calcium ion induces mitochondrial dysfunction leading to caspase activation and eventual apoptosis (Xiong et al., 1999; Pearn et al., 2017). Secondary, or delayed, injury following TBI is believed to occur due to multiple physiologic processes including free radical injury, inflammation, and glutamatergic excitotoxicity (Lenzlinger et al., 2001; Morganti-Kossmann et al., 2002; Yi and Hazell, 2006; O'Connell and Littleton-Kearney, 2013).

\section{CURRENT THERAPIES UNDER INVESTIGATION}

\section{N-Acetyl Cysteine}

$\mathrm{N}$-acetyl cysteine has been shown to have significant neuroprotective effects in various animal models, particularly in ameliorating the effects of secondary neuronal injury as a result of TBI. Experimental rat models have confirmed the beneficial antioxidant properties of NAC when used to treat brain injury. NAC acts by upregulating the level of GSH, a combination of L-glutamic acid, L-cysteine, and glycine, within the brain. Administration of NAC maintains high GSH levels in the brain which acts as a free radical scavenger and as an antioxidant itself (Ellis et al., 1991; Xiong et al., 1999; Chen et al., 2008). The underlying pathophysiologic processes resulting from TBI lead to increased risk of neurodegenerative illnesses such as $\mathrm{AD}$ and PD (Ikonomovic et al., 2004; Acosta et al., 2013; Franzblau et al., 2013; Chauhan, 2014; Pearn et al., 2017; Gardner et al., 2018). NAC provides a source of cysteine, a precursor to GSH, which can be used to alleviate reactive oxygen species (ROS)-mediated complex I damage in mitochondria of the substantia nigra in PD (Jha et al., 2000; Martínez Banaclocha, 2000; Banaclocha, 2001). NAC also reduces tau and beta-amyloid deposition and acts as an anti-inflammatory agent in treating $\mathrm{AD}$ via the upregulation of $\mathrm{GSH}$, displaying its efficacy in not only treating TBI itself but also subsequent neurodegenerative conditions that are associated with TBI in rat and mice models (Tucker et al., 2005; Acosta et al., 2013; Franzblau et al., 2013; Joy et al., 2018; Tardiolo et al., 2018). A double-blind placebo-controlled human trial was used to evaluate efficacy of NAC in patients with blast-induced mild TBI (Hoffer et al., 2013). The treatment group received $2 \mathrm{~g}$ of NAC twice daily for the first 4 days followed by $1.5 \mathrm{~g}$ of NAC twice daily for 3 days. All patients were evaluated for dizziness, headache, hearing loss, memory loss, sleep disturbances, and neurocognitive dysfunction following 7 days of treatment. Significant improvement $(p<0.01)$ with regards to these symptoms were seen 7 days post-treatment in those receiving NAC within $24 \mathrm{~h}$ of injury. Additionally, the treatment group had $86 \%$ chance of recovery. Outcomes from this study warrant further investigation on long-term outcomes of NAC treatment in TBI (Table 1).

The antioxidant properties of NAC make it particularly useful in treating dysfunction resulting from TBI by mitigating the damaged mitochondrial production of ROS. However, low bioavailability in the brain has created interest in $\mathrm{N}$-acetyl cysteine amide (NACA) a form of NAC with higher cellular permeability. Recent animal studies have shown NACA to be significantly better than NAC in reducing oxidative stress when treating TBI (Pandya et al., 2014).

Treatment with NACA in rats has also been shown to protect the blood-brain barrier (BBB) and maintain brain homeostasis by alleviating oxidative stress caused by blast overpressure induced TBI (Kawoos et al., 2019). NACA promoted an antioxidant effect via activation of the nuclear factor erythroid 2-related factor 2 (Nrf2) - antioxidant response element (ARE) pathway. NACA also displayed antiapoptotic properties following TBI. Both antioxidant and antiapoptotic effects are induced by modulation of the ubiquitin protease system via activation of the Nrf2ARE pathway (Ding et al., 2017; Zhou et al., 2018). It is important to note that these studies utilized blast overpressure techniques. Additional studies investigating NACA using "true" blast models as described by Rubovitch et al. (2011) rather than a "blast tube" may provide further insight into the protective effects of NACA.

\section{Minocycline}

Minocycline (MINO), a tetracycline antibiotic, has been shown to offer neuroprotective properties on its own and in combination with NAC and NACA. Rat models have supported the efficacy of MINO in treating neurological impairment arising from TBI (Haber et al., 2018; Zhang et al., 2020). In a mild controlled cortical impact model, MINO + NAC improved memory and cognition in rats and repaired white matter damage by protecting oligodendrocytes (Haber et al., 2018). In a controlled head injury (CHI) model of TBI, loss of oligodendrocytes was also observed. $\mathrm{MINO}+$ NAC provided protection against oligodendrocyte apoptosis during days $2-14$ when dosed at $12 \mathrm{~h}$ post-TBI. MINO alone did not protect against initial oligodendrocyte damage when dosed $12 \mathrm{~h}$ post-TBI; however, full recovery was seen on day 14, suggesting that MINO alone operates via a different mechanism than MINO + NAC (Sangobowale et al., 2018). MINO alone acts by temporarily inhibiting microglial 
activation and reducing TBI-induced locomotor activity leading to improved long-term outcomes post-TBI (Homsi et al., 2010). Despite MINO proving to be safe in treating TBI in phase 1 trials, a human study on 15 patients greater than 6 months post moderate/severe TBI, receiving $100 \mathrm{mg}$ MINO two times daily, indicated inhibition of chronic microglial activation which may have reparative effects but ultimately resulted in increased neurodegeneration indicated by increased levels of plasma neurofilament light chain (Scott et al., 2018; Meythaler et al., 2019). Though MINO alone may not be efficacious in treating TBI, human trials involving MINO and NAC together may be warranted.

\section{(-)-Phenserine}

Phenserine is an anti-acetylcholinesterase agent with additional non-cholinergic properties that was originally developed to treat AD (Greig et al., 1995). However, PHEN has the potential to be repurposed for treating TBI. PHEN anti-acetylcholinesterase activity has been shown to reduce neuroinflammation, alleviate amyloid deposition, and prevent apoptosis as well as mitigate multiple different mechanisms of secondary injury (Kadir et al., 2008; Poole and Agrawal, 2008; Hsueh et al., 2019; Lecca et al., 2019).

A study by Lecca et al. (2019) investigated the effects of PHEN (5 mg/kg) in mitigating apoptosis and neuroinflammation

TABLE 1 | Summary of human trials for repurposed drugs in TBI.

\begin{tabular}{|c|c|c|c|c|c|c|c|}
\hline & $\begin{array}{l}\text { Reference (study } \\
\text { design) }\end{array}$ & $\begin{array}{l}N(\% \\
\text { male) }\end{array}$ & $\begin{array}{l}\text { Mean age } \\
\text { (range) }\end{array}$ & Control & Dose & Outcome measures & Findings \\
\hline \multirow[t]{2}{*}{$\begin{array}{l}\mathrm{N} \text {-acetyl } \\
\text { cysteine }\end{array}$} & $\begin{array}{l}\text { Hoffer et al., } 2013 \\
\text { (phase III) }\end{array}$ & $81(99 \%)$ & $\begin{array}{l}22 \text { years } \\
(18-43)\end{array}$ & Placebo & $\begin{array}{l}2 \mathrm{~g} \text { BID for } \\
4 \text { days } 1.5 \mathrm{~g} \\
\text { BID for } 3 \text { days }\end{array}$ & $\begin{array}{l}\text { 1. Controlled oral world } \\
\text { association test, animal } \\
\text { naming test, trail } \\
\text { making test } 2 \text {. Clinical } \\
\text { assessment for hearing } \\
\text { loss, headache, } \\
\text { balance }\end{array}$ & $\begin{array}{l}\text { 1. Improved cognitive } \\
\text { function } 2 \text {. Amelioration } \\
\text { of mild TBI symptoms }\end{array}$ \\
\hline & $\begin{array}{l}\text { Amen et al., } 2011 \\
\text { (Prospective) }\end{array}$ & 30 (100\%) & $N R$ & Self-matched & $N R$ & $\begin{array}{l}\text { 1. SPECT image } \\
\text { analysis 2. MicroCog } \\
\text { Assessment of } \\
\text { Cognitive Functioning }\end{array}$ & $\begin{array}{l}\text { 1. Increased cerebral } \\
\text { blood flow 2. Improved } \\
\text { cognitive function }\end{array}$ \\
\hline \multirow[t]{3}{*}{ Minocycline } & $\begin{array}{l}\text { Meythaler et al., } 2019 \\
\text { (phase Ila) }\end{array}$ & $15(80 \%)$ & $\begin{array}{l}43 \text { years } \\
(21-71)\end{array}$ & Self-matched & $\begin{array}{l}\text { Tier 1: } 200 \mathrm{mg} \\
\text { BID for } 7 \text { days } \\
\text { Tier 2: } 400 \mathrm{mg} \\
\text { BID for } 7 \text { days }\end{array}$ & $\begin{array}{l}\text { 1. Disability rating scale } \\
\text { 2. Neurocognitive } \\
\text { outcome measures } 3 . \\
\text { Serum biomarkers, } \\
\text { laboratory analysis }\end{array}$ & $\begin{array}{l}\text { 1. Trend toward } \\
\text { improved DRS for } \\
\text { higher dose } 2 \text {. Safe for } \\
\text { use in TBI at } 2 \times \text { dose } \\
\text { recommended for } \\
\text { infection }\end{array}$ \\
\hline & $\begin{array}{l}\text { Koulaeinejad et al., } \\
2019 \text { (phase III) }\end{array}$ & 34 (88\%) & $\begin{array}{l}42.5 \text { years } \\
(18-73)\end{array}$ & Placebo & $\begin{array}{l}100 \mathrm{mg} \text { BID for } \\
7 \text { days }\end{array}$ & $\begin{array}{l}\text { 1. S100B 2. NSE } 3 . \\
\text { GCS }\end{array}$ & $\begin{array}{l}\text { 1. Significant reduction } \\
\text { S100B and NSE }\end{array}$ \\
\hline & $\begin{array}{l}\text { Scott et al., } 2018 \\
\text { (cross sectional) }\end{array}$ & 15 (87\%) & $\begin{array}{l}42.3 \text { years } \\
(23-61)\end{array}$ & Control (no treatment) & $\begin{array}{l}100 \text { mg BID for } \\
12 \text { weeks }\end{array}$ & $\begin{array}{l}\text { 1. PET 2. MRI } 3 \text {. } \\
\text { Plasma axonal protein } \\
\text { NFL }\end{array}$ & $\begin{array}{l}\text { 1. Reduced chronic } \\
\text { microglial activation } 2 \text {. } \\
\text { Increased plasma NFL } \\
\text { 3. Microglial activation } \\
\text { has reparative effects in } \\
\text { late stage TBI }\end{array}$ \\
\hline
\end{tabular}

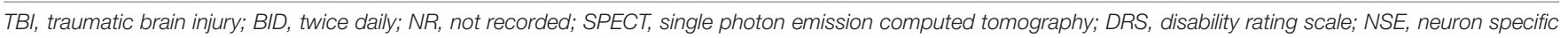
enolase; GCS, Glasgow Coma Scale; PET, positron emission tomography; MRI, magnetic resonance imaging; NFL, neurofilament light.

TABLE 2 | Ongoing human clinical trials.

\begin{tabular}{|c|c|c|c|c|c|c|}
\hline Clinical trial identifier & Status & Title & Study design & Drug & Intervention arms & $\begin{array}{l}\text { Primary outcome } \\
\text { measure }\end{array}$ \\
\hline NCT03241732 & Recruiting & $\begin{array}{l}\text { PET-MRI and the effect } \\
\text { of } \mathrm{N} \text {-acetyl cysteine } \\
\text { and anti-inflammatory } \\
\text { diet in TBI }\end{array}$ & $\begin{array}{l}\text { Non- } \\
\text { randomized, } \\
\text { crossover }\end{array}$ & NAC & $\begin{array}{l}\text { 1. Dietary arm 2. IV/PO } \\
\text { arm 3. Control arm }\end{array}$ & $\begin{array}{l}\text { FDG-PET to measure } \\
\text { inflammation and } \\
\text { oxidative damage in the } \\
\text { brain }\end{array}$ \\
\hline NCT04291066 & Active, not recruiting & $\begin{array}{l}\text { Prospective analysis of } \\
\text { the use of } \mathrm{N} \text {-acetyl } \\
\text { cysteine and vitamins in } \\
\text { the treatment of } \mathrm{TBI} \text { in } \\
\text { geriatric patients }\end{array}$ & $\begin{array}{l}\text { Randomized, } \\
\text { prospective }\end{array}$ & $\begin{array}{l}\text { NAC and oral } \\
\text { multivitamins }\end{array}$ & $\begin{array}{l}\text { 1. Experimental } 2 . \\
\text { Non-treatment (routine } \\
\text { care) }\end{array}$ & $\begin{array}{l}\text { Determine } \\
\text { improvement in } \\
\text { somatic, cognitive, and } \\
\text { emotional } \\
\text { post-concussion } \\
\text { symptoms }\end{array}$ \\
\hline
\end{tabular}

NAC, N-acetyl cysteine; TBI, traumatic brain injury; IV, intravenous; PO, per os; FDG-PET, fluorodeoxyglucose-positron emission tomography. 
in both wild-type (WT) and amyloid-precursor protein (APP)/presenilin 1 (PSEN1) expressing AD mice (APP/PS1 mice) when exposed to mild TBI (mTBI). PHEN was found to be well tolerated in exposed mice. Exposure to mTBI resulted in increased size of microglial cell bodies and increased production of IB1A 1 and TNF- $\alpha$. PHEN reduced inflammation by decreasing the production of IB1A1 and TNF- $\alpha$ in microglial cells in a dosedependent manner after exposure to mTBI in both WT and APP/PS1 mice. This anti-inflammatory action was observed in both hippocampal and cortical areas in WT and APP/PS1 mice. An increase in glial fibrillary acidic protein IR (GFAP IR), an astrocyte marker, was also noted in hippocampal in cortical areas. PHEN was shown to fully reverse the increase in GFAP IR in both WT and APP/PS1 mouse models (Lecca et al., 2019). PHEN has demonstrated both anti-apoptotic effects through upregulation of Bcl-2 and BDNF expression while also decreasing pro-apoptotic factors such as caspase-3, APP, and GFAP (Chang et al., 2017). Similar data was also seen following controlled cortical impact injury in moderate TBI. In addition to treating cell death, PHEN has also had positive effects on reducing intracranial pressure, measured with lateral ventricle size, and contusion volume. Treatment of $2.5 \mathrm{mg} / \mathrm{kg}$ twice daily for 5 days post controlled cortical impact injury in mice reduced both contusion volume and intracranial pressure (Hsueh et al., 2019).

Phenserine administration post mTBI not only alleviates primary cellular damage but also shows efficacy in treating secondary TBI syndromes such as AD (Ikonomovic et al., 2004; Acosta et al., 2013; Franzblau et al., 2013; Chauhan, 2014). Treatment with PHEN in WT mice exposed to mTBI displayed significant dose-dependent recovery of both visual and spatial memory (Lecca et al., 2019). Levels of APP and alpha-synuclein, which are present in $\mathrm{AD}$ and $\mathrm{PD}$, respectively, were decreased by treatment of PHEN (Marutle et al., 2007; Mikkilineni et al., 2012; Chang et al., 2017).

While many studies have demonstrated the protective effects of PHEN due to its anti-cholinergic activity, recent studies have also shown that many of the protective effects of PHEN maybe mediated by multiple non-cholinergic mechanism. A study by Tweedie et al. (2016) evaluated the non-cholinergic actions of PHEN on mTBI mice following a 2 days wash out when cholinergic actions were no longer present. PHEN dosed at 2.5 and $5.0 \mathrm{mg} / \mathrm{kg}$ twice daily for 5 days mitigated oxidative stress as measured by activity and protein levels of superoxide dismutase and glutathione peroxidase. Furthermore, PHEN was shown to reverse hippocampal gene expression associated with lipid peroxidation and development of $\mathrm{AD}$ in mTBI mice (Tweedie et al., 2016). Thus therapeutic benefits of PHEN in mitigating

\section{REFERENCES}

Acosta, S. A., Tajiri, N., Shinozuka, K., Ishikawa, H., Grimmig, B., Diamond, D. M., et al. (2013). Long-term upregulation of inflammation and suppression of cell proliferation in the brain of adult rats exposed to traumatic brain injury using the controlled cortical impact model. PLoS One 8:e53376. doi: 10.1371/journal.pone.0053376

Adminstration FD. (1971). Available online at: https://www.accessdata.fda.gov/ drugsatfda_docs/label/2020/213690s000lbl.pdf (accessed January 11, 2021). effects of TBI are likely related to both non-cholinergic features unique to PHEN as well as cholinergic properties shared by other anticholinesterases.

\section{OTHER DRUGS UNDER INVESTIGATION}

Many drugs are currently being evaluated as potential treatments for TBI. Though the exact mechanism is unknown, amantadine appears to act as an NMDA receptor antagonist and an indirect dopamine agonist. Placebo-controlled studies involving amantadine as a potential therapeutic agent have shown efficacy in accelerating recovery time and functional improvement following TBI (Meythaler et al., 2002; Giacino et al., 2012). Neurosteroids have also been considered to be repurposed to treat TBI. Progesterone, a neurosteroid, has been shown to promote neurogenesis by increasing the release of BDNF, NGF, and IGF (Stein and Sayeed, 2019). In a randomized controlled trial, progesterone administration lowered mortality 3 months post-TBI. Though it did not show significant benefit 6 months post-TBI, administration in combination with other drugs may support its utility (Pan et al., 2019). A summary of ongoing human clinical trials for the aforementioned repurposed drugs can be found in Table 2 .

\section{CONCLUSION}

While effective pharmacological treatments have not yet been approved for the treatment of TBI, drug reproposing may help accelerate identification of effective pharmacological therapies. Limited human trials investigating NAC have shown promise and demonstrated neuroprotective effects in mTBI patients. Additional pre-clinical animal studies on NACA, MINO, and PHEN have also demonstrated efficacy in neuroprotection and mitigating delayed sequela from TBI. Future studies, particularly those involving human trials, are needed to elucidate the benefit of these reproposed drugs in mitigating the acute and delayed effects of TBI.

\section{AUTHOR CONTRIBUTIONS}

SP, MG, and MH: data analysis, manuscript preparation, and manuscript editing. WS, $\mathrm{AH}$, and $\mathrm{BH}$ : manuscript preparation and manuscript editing. All authors contributed to the article and approved the submitted version.

Amen, D. G., Wu, J. C., Taylor, D., and Willeumier, K. (2011). Reversing brain damage in former NFL players: implications for traumatic brain injury and substance abuse rehabilitation. J. Psychoactive Drugs 43, 1-5. doi: 10.1080/ 02791072.2011.566489

Banaclocha, M. M. (2001). Therapeutic potential of N-acetylcysteine in age-related mitochondrial neurodegenerative diseases. Med. Hypotheses 56, 472-477. doi: 10.1054/mehy.2000.1194

Chang, C.-F., Lai, J.-H., Wu, J. C.-C., Greig, N. H., Becker, R. E., Luo, Y., et al. (2017). (-)-Phenserine inhibits neuronal apoptosis following 
ischemia/reperfusion injury. Brain Res. 1677, 118-128. doi: 10.1016/j.brainres. 2017.09.015

Chauhan, N. B. (2014). Chronic neurodegenerative consequences of traumatic brain injury. Restor. Neurol. Neurosci. 32, 337-365. doi: 10.3233/rnn- 130354

Chen, G., Shi, J., Hu, Z., and Hang, C. (2008). Inhibitory effect on cerebral inflammatory response following traumatic brain injury in rats: a potential neuroprotective mechanism of $\mathrm{N}$-acetylcysteine. Mediators Inflamm. 2008:716458.

Dewan, M. C., Rattani, A., Gupta, S., Baticulon, R. E., Hung, Y.-C., Punchak, M., et al. (2018). Estimating the global incidence of traumatic brain injury. J. Neurosurg. [Epub ahead of print].

Ding, H., Wang, X., Wang, H., Zhu, L., Wang, Q., Jia, Y., et al. (2017). Nrf2-ARE signaling provides neuroprotection in traumatic brain injury via modulation of the ubiquitin proteasome system. Neurochem. Int. 111, 32-44. doi: 10.1016/j. neuint.2017.04.016

Djordjevic, J., Sabbir, M. G., and Albensi, B. C. (2016). Traumatic brain injury as a risk factor for Alzheimer's disease: is inflammatory signaling a key player? Curr. Alzheimer. Res. 13, 730-738. doi: 10.2174/1567205013666160222110320

Du, X., West, M. B., Cheng, W., Ewert, D. L., Li, W., Saunders, D., et al. (2016). Ameliorative effects of antioxidants on the hippocampal accumulation of pathologic tau in a rat model of blast-induced traumatic brain injury. Oxid. Med. Cell Longev. 2016:4159357.

Eakin, K., Baratz-Goldstein, R., Pick, C. G., Zindel, O., Balaban, C. D., Hoffer, M. E., et al. (2014). Efficacy of $\mathrm{N}$-acetyl cysteine in traumatic brain injury. PLoS One 9:e90617. doi: 10.1371/journal.pone.0090617

Ellis, E. F., Dodson, L. Y., and Police, R. J. (1991). Restoration of cerebrovascular responsiveness to hyperventilation by the oxygen radical scavenger n-acetylcysteine following experimental traumatic brain injury. J. Neurosurg. 75, 774-779. doi: 10.3171/jns.1991.75.5.0774

Faul, M., Wald, M. M., Rutland-Brown, W., Sullivent, E. E., and Sattin, R. W. (2007). Using a cost-benefit analysis to estimate outcomes of a clinical treatment guideline: testing the brain trauma foundation guidelines for the treatment of severe traumatic brain injury. J. Trauma. Acute Care Surg. 63:1271. doi: $10.1097 /$ ta.0b013e3181493080

Faul, M., Xu, L., Wald, M. M., Coronado, V., and Dellinger, A. M. (2010). Traumatic brain injury in the United States: national estimates of prevalence and incidence, 2002-2006. Inj. Prev. 16(Suppl. 1), A268-A.

Franzblau, M., Gonzales-Portillo, C., Gonzales-Portillo, G. S., Diamandis, T., Borlongan, M. C., Tajiri, N., et al. (2013). Vascular damage: a persisting pathology common to Alzheimer's disease and traumatic brain injury. Med. Hypotheses 81, 842-845. doi: 10.1016/j.mehy.2013.09.012

Gardner, R. C., Byers, A. L., Barnes, D. E., Li, Y., Boscardin, J., and Yaffe, K. (2018). Mild TBI and risk of Parkinson disease: a chronic effects of neurotrauma consortium study. Neurology 90, e1771-e1779.

Giacino, J. T., Whyte, J., Bagiella, E., Kalmar, K., Childs, N., Khademi, A., et al. (2012). Placebo-controlled trial of amantadine for severe traumatic brain injury. N. Engl. J. Med. 366, 819-826.

Goldman, S. M., Tanner, C. M., Oakes, D., Bhudhikanok, G. S., Gupta, A., and Langston, J. W. (2006). Head injury and Parkinson's disease risk in twins. Ann. Neurol. 60, 65-72. doi: 10.1002/ana.20882

Greig, N. H., Pei, X. F., Soncrant, T. T., Ingram, D. K., and Brossi, A. (1995). Phenserine and ring $\mathrm{C}$ hetero-analogues: drug candidates for the treatment of Alzheimer's disease. Med. Res. Rev. 15, 3-31. doi: 10.1002/med.2610150103

Haber, M., James, J., Kim, J., Sangobowale, M., Irizarry, R., Ho, J., et al. (2018). Minocycline plus $\mathrm{N}$-acteylcysteine induces remyelination, synergistically protects oligodendrocytes and modifies neuroinflammation in a rat model of mild traumatic brain injury. J. Cereb. Blood Flow Metab. 38, 1312-1326. doi: $10.1177 / 0271678 \times 17718106$

Hoffer, B. J., Pick, C. G., Hoffer, M. E., Becker, R. E., Chiang, Y. H., and Greig, N. H. (2017). Repositioning drugs for traumatic brain injury - N-acetyl cysteine and Phenserine. J. Biomed. Sci. 24:71. doi: 10.1002/9781118656303.ch5

Hoffer, M. E., Balaban, C., Slade, M. D., Tsao, J. W., and Hoffer, B. (2013). Amelioration of acute sequelae of blast induced mild traumatic brain injury by $\mathrm{N}$-acetyl cysteine: a double-blind, placebo controlled study. PLoS One 8:e54163. doi: 10.1371 /journal.pone. 0054163

Homsi, S., Piaggio, T., Croci, N., Noble, F., Plotkine, M., Marchand-Leroux, C., et al. (2010). Blockade of acute microglial activation by minocycline promotes neuroprotection and reduces locomotor hyperactivity after closed head injury in mice: a twelve-week follow-up study. J. Neurotrauma. 27, 911-921. doi: 10.1089/neu.2009.1223

Hsueh, S.-C., Lecca, D., Greig, N. H., Wang, J.-Y., Selman, W., Hoffer, B. J., et al. (2019). (-)-Phenserine ameliorates contusion volume, neuroinflammation, and behavioral impairments induced by traumatic brain injury in mice. Cell Transplant. 28, 1183-1196. doi: 10.1177/0963689719854693

Ikonomovic, M. D., Uryu, K., Abrahamson, E. E., Ciallella, J. R., Trojanowski, J. Q., Lee, V. M. Y., et al. (2004). Alzheimer's pathology in human temporal cortex surgically excised after severe brain injury. Exp. Neurol. 190, 192-203. doi: 10.1016/j.expneurol.2004.06.011

Jennett, B., Snoek, J., Bond, M. R., and Brooks, N. (1981). Disability after severe head injury: observations on the use of the Glasgow Outcome Scale. J. Neurol. Neurosurg. Psychiatry 44, 285-293. doi: 10.1136/jnnp.44.4.285

Jha, N., Jurma, O., Lalli, G., Liu, Y., Pettus, E. H., Greenamyre, J. T., et al. (2000). Glutathione depletion in PC12 results in selective inhibition of mitochondrial complex I activity. Implications for Parkinson's disease. J. Biol. Chem. 275, 26096-26101. doi: 10.1074/jbc.m000120200

Joy, T., Rao, M. S., and Madhyastha, S. (2018). N-Acetyl cysteine supplement minimize tau expression and neuronal loss in animal model of Alzheimer's disease. Brain Sci. 8:185. doi: 10.3390/brainsci8100185

Kadir, A., Andreasen, N., Almkvist, O., Wall, A., Forsberg, A., Engler, H., et al. (2008). Effect of phenserine treatment on brain functional activity and amyloid in Alzheimer's disease. Ann. Neurol. 63, 621-631. doi: 10.1002/ana.21345

Kawoos, U., Abutarboush, R., Zarriello, S., Qadri, A., Ahlers, S. T., McCarron, R. M., et al. (2019). N-acetylcysteine amide ameliorates blast-induced changes in blood-brain barrier integrity in rats. Front. Neurol. 10:650. doi: 10.3389/ fneur.2019.00650

Koulaeinejad, N., Haddadi, K., Ehteshami, S., Shafizad, M., Salehifar, E., Emadian, O., et al. (2019). Effects of minocycline on neurological outcomes in patients with acute traumatic brain injury: a pilot study. Iran J. Pharm. Res. 18, 10861096. doi: $10.22037 /$ ijpr.2019.1100677

Lecca, D., Bader, M., Tweedie, D., Hoffman, A. F., Jung, Y. J., Hsueh, S.C., et al. (2019). (-)-Phenserine and the prevention of pre-programmed cell death and neuroinflammation in mild traumatic brain injury and Alzheimer's disease challenged mice. Neurobiol. Dis. 130:104528. doi: 10.1016/j.nbd.2019.10 4528

Lenzlinger, P. M., Morganti-Kossmann, M. C., Laurer, H. L., and McIntosh, T. K. (2001). The duality of the inflammatory response to traumatic brain injury. Mol. Neurobiol. 24, 169-181. doi: 10.1385/mn:24:1-3:169

Martínez Banaclocha, M. (2000). N-acetylcysteine elicited increase in complex I activity in synaptic mitochondria from aged mice: implications for treatment of Parkinson's disease. Brain Res. 859, 173-175. doi: 10.1016/s0006-8993(00) 02005-9

Marutle, A., Ohmitsu, M., Nilbratt, M., Greig, N. H., Nordberg, A., and Sugaya, K. (2007). Modulation of human neural stem cell differentiation in Alzheimer (APP23) transgenic mice by phenserine. Proc. Natl. Acad. Sci. U.S.A. 104, 12506-12511. doi: 10.1073/pnas.0705346104

Mendez, M. F. (2017). What is the relationship of traumatic brain injury to dementia? J. Alzheimers Dis. 57, 667-681. doi: 10.3233/jad- 161002

Meythaler, J., Fath, J., Fuerst, D., Zokary, H., Freese, K., Martin, H. B., et al. (2019). Safety and feasibility of minocycline in treatment of acute traumatic brain injury. Brain Inj. 33, 679-689. doi: 10.1080/02699052.2019.1566968

Meythaler, J. M., Brunner, R. C., Johnson, A., and Novack, T. A. (2002). Amantadine to improve neurorecovery in traumatic brain injury-associated diffuse axonal injury: a pilot double-blind randomized trial. J. Head. Trauma. Rehabil. 17, 300-313. doi: 10.1097/00001199-200208000-00004

Mikkilineni, S., Cantuti-Castelvetri, I., Cahill, C. M., Balliedier, A., Greig, N. H., and Rogers, J. T. (2012). The anticholinesterase phenserine and its enantiomer posiphen as 5'untranslated-region-directed translation blockers of the Parkinson's alpha synuclein expression. Parkinsons Dis. 2012:142372.

Morganti-Kossmann, M. C., Rancan, M., Stahel, P. F., and Kossmann, T. (2002). Inflammatory response in acute traumatic brain injury: a double-edged sword. Curr. Opin. Crit. Care 8, 101-105. doi: 10.1097/00075198-200204000-00002

O'Connell, K. M., and Littleton-Kearney, M. T. (2013). The role of free radicals in traumatic brain injury. Biol. Res. Nurs. 15, 253-263. doi: 10.1177/ 1099800411431823

Pan, Z.-Y., Zhao, Y.-H., Huang, W.-H., Xiao, Z.-Z., and Li, Z.-Q. (2019). Effect of progesterone administration on the prognosis of patients with severe traumatic 
brain injury: a meta-analysis of randomized clinical trials. Drug Des. Devel. Ther. 13, 265-273. doi: 10.2147/dddt.s192633

Pandya, J. D., Readnower, R. D., Patel, S. P., Yonutas, H. M., Pauly, J. R., Goldstein, G. A., et al. (2014). N-acetylcysteine amide confers neuroprotection, improves bioenergetics and behavioral outcome following TBI. Exp. Neurol. 257, 106113. doi: 10.1016/j.expneurol.2014.04.020

Pearn, M. L., Niesman, I. R., Egawa, J., Sawada, A., Almenar-Queralt, A., Shah, S. B., et al. (2017). Pathophysiology associated with traumatic brain injury: current treatments and potential novel therapeutics. Cell Mol. Neurobiol. 37, 571-585. doi: 10.1007/s10571-016-0400-1

Poole, N. A., and Agrawal, N. (2008). Cholinomimetic agents and neurocognitive impairment following head injury: a systematic review. Brain Inj. 22, 519-534. doi: 10.1080/02699050802132495

Prescott, L. F., Illingworth, R. N., Critchley, J. A., Stewart, M. J., Adam, R. D., and Proudfoot, A. T. (1979). Intravenous N-acetylcystine: the treatment of choice for paracetamol poisoning. Br. Med. J. 2, 1097-1100. doi: 10.1136/bmj.2.6198. 1097

Ray, S. K., Dixon, C. E., and Banik, N. L. (2002). Molecular mechanisms in the pathogenesis of traumatic brain injury. Histol. Histopathol. 17, 1137-1152.

Rubovitch, V., Ten-Bosch, M., Zohar, O., Harrison, C. R., Tempel-Brami, C., Stein, E., et al. (2011). A mouse model of blast-induced mild traumatic brain injury. Exp. Neurol. 232, 280-289.

Sangobowale, M. A., Grin'kina, N. M., Whitney, K., Nikulina, E., St LaurentAriot, K., Ho, J. S., et al. (2018). Minocycline plus $\mathrm{N}$-acetylcysteine reduce behavioral deficits and improve histology with a clinically useful time window. J. Neurotrauma. 35, 907-917. doi: 10.1089/neu.2017.5348

Scott, G., Zetterberg, H., Jolly, A., Cole, J. H., De Simoni, S., Jenkins, P. O., et al. (2018). Minocycline reduces chronic microglial activation after brain trauma but increases neurodegeneration. Brain 141, 459-471. doi: 10.1093/brain/ awx339

Stein, D. G., and Sayeed, I. (2019). Repurposing and repositioning neurosteroids in the treatment of traumatic brain injury: a report from the trenches. Neuropharmacology 147, 66-73. doi: 10.1016/j.neuropharm.2018.04.006

Tagliaferri, F., Compagnone, C., Korsic, M., Servadei, F., and Kraus, J. (2006). A systematic review of brain injury epidemiology in Europe. Acta Neurochir. 148, 255-268. doi: 10.1007/s00701-005-0651-y

Tardiolo, G., Bramanti, P., and Mazzon, E. (2018). Overview on the effects of N-Acetylcysteine in neurodegenerative diseases. Molecules 23:3305. doi: 10 . 3390/molecules23123305
Tucker, S., Ahl, M., Bush, A., Westaway, D., Huang, X., and Rogers, J. T. (2005). Pilot study of the reducing effect on amyloidosis in vivo by three FDA pre-approved drugs via the Alzheimer's APP 5' untranslated region. Curr. Alzheimer Res. 2, 249-254. doi: 10.2174/156720505358 5855

Tweedie, D., Fukui, K., Li, Y., Yu, Q. S., Barak, S., Tamargo, I. A., et al. (2016). Cognitive impairments induced by concussive mild traumatic brain injury in mouse are ameliorated by treatment with phenserine via multiple noncholinergic and cholinergic mechanisms. PLoS One 11:e0156493. doi: 10.1371/ journal.pone.0156493

Xiong, Y., Peterson, P. L., and Lee, C. P. (1999). Effect of N-acetylcysteine on mitochondrial function following traumatic brain injury in rats. J. Neurotrauma. 16, 1067-1082. doi: 10.1089/neu.1999.16. 1067

Xiong, Y., Zhang, Y., Mahmood, A., and Chopp, M. (2015). Investigational agents for treatment of traumatic brain injury. Expert Opin. Investig. Drugs 24, $743-$ 760. doi: 10.1517/13543784.2015.1021919

Yi, J. H., and Hazell, A. S. (2006). Excitotoxic mechanisms and the role of astrocytic glutamate transporters in traumatic brain injury. Neurochem. Int. 48, 394-403. doi: 10.1016/j.neuint.2005.12.001

Zhang, L., Xiao, H., Yu, X., and Deng, Y. (2020). Minocycline attenuates neurological impairment and regulates iron metabolism in a rat model of traumatic brain injury. Arch. Biochem. Biophys. 682:108302. doi: 10.1016/j.abb. 2020.108302

Zhou, Y., Wang, H. D., Zhou, X. M., Fang, J., Zhu, L., and Ding, K. (2018). $\mathrm{N}$-acetylcysteine amide provides neuroprotection via Nrf2-ARE pathway in a mouse model of traumatic brain injury. Drug Des. Devel. Ther. 12, 4117-4127. doi: $10.2147 /$ dddt.s 179227

Conflict of Interest: The authors declare that the research was conducted in the absence of any commercial or financial relationships that could be construed as a potential conflict of interest.

Copyright (c) 2021 Ghiam, Patel, Hoffer, Selman, Hoffer and Hoffer. This is an openaccess article distributed under the terms of the Creative Commons Attribution License (CC BY). The use, distribution or reproduction in other forums is permitted, provided the original author(s) and the copyright owner(s) are credited and that the original publication in this journal is cited, in accordance with accepted academic practice. No use, distribution or reproduction is permitted which does not comply with these terms. 